\title{
MÁS ALLÁ DEL URBANISMO SITUACIONISTA. ACERCA DE NEW BABYLON DE CONSTANT
}

Juan Ignacio Arias

Alexis Candia-Cáceres

Patricio Landaeta

Universidad de Playa Ancha, Chile

Data recepción: 2016/09/26

Data aceptación: 2018/03/06

Contacto autores: juan.arias@upla.cl; ivan.candia@upla.cl; patricio.landaeta@upla.cl

ORCID: https://orcid.org/0000-0001-8985-9732

ORCID: https://orcid.org/0000-0001-7674-4768

ORCID: https://orcid.org/0000-0002-3713-4768

\section{RESUMEN}

La propuesta urbanística del situacionismo constituye una apuesta teórico-práctica enfrentada a la planificación del urbanismo moderno, que consolida el "aislamiento colectivo" y la circulación para el consumo como matriz de la vida urbana. Contra ello los situacionistas insisten en la necesidad de apropiarnos, como individuos libres, del condicionamiento que históricamente habría puesto en juego la arquitectura y el urbanismo funcionalista. New Babylon, proyecto de Constant Nieuwenhuys, nos ofrece una síntesis de tales ideas en el diseño de un espacio urbano orientado a la creación colectiva de un "lugar común".

Palabras clave: Guy Debord, New Babylon, Constant, Urbanismo unitario, Nuevo espacio social

\section{ABSTRACT}

The Situationist urban proposal is a theoretical and practical stance against modern urban planning, which consolidates "collective isolation" and car-based consumerism as a matrix of urban life. In responding to this, the Situationists stress the need to appropriate, as free individuals, the conditioning that has historically imposed functionalist architecture and urbanism. Constant Nieuwenhuys' New Babylon offers up a synthesis of these ideas through the design of an urban space that seeks the collective creation of a "common place".

Keywords: Guy Debord, New Babylon, Constant, unitarian urbanism, new social space

Introducción. Alienación y aislamiento colectivo

Entre los años 1958 y 1961, Guy Debord junto a sus camaradas de la Internacional Situacionista publican los seis primeros números de la revista homónima donde plasman el más encarnizado rechazo a la vida cotidiana en la metrópolis capitalista para entonces diseminada por doquier. Lo que cabe todavía destacar a más de medio siglo de esos escritos es que la crítica situacionista, que se enfoca en combatir el aislamiento colectivo obligado de millares de seres urbanos, indaga en las alternativas para superar la depotenciada vida urbana, reducida a mero sucedáneo de relación social en el ocio cooptado por el consumismo de una sociedad invadida por los principios del mer- 
cado. La certeza de Debord y sus colaboradores es que la confrontación con aquello que aparece como lo más superficial, el uso del territorio, permitirá penetrar en el mecanismo de producción de la vida alienada. En efecto, con vistas a conjurar la alienación es que la Internacional Situacionista lleva adelante la crítica del urbanismo moderno, principal garante de la despolitización del ciudadano y de su reducción a consumidor y espectador pasivo'.

La lucha emprendida por los situacionistas contra los profesionales del territorio -urbanismo y arquitectura moderna- no es accidental ni menos desinteresada. Podría afirmarse que el urbanismo moderno o funcionalista ${ }^{2}$ asume y renueva los principios y objetivos de la policía moderna que tenía bajo su cuidado la ciudad y el bienestar de las poblaciones para acrecentar las fuerzas del estado³. En esa dirección Michel Foucault ha señalado que, una vez que disputa con la política el título de maestra de la ciudad, la arquitectura salta hacia una nueva escala: abandonando el palacio del soberano y la representación de su poder para la organización de la ciudad, se despliega en el territorio del estado y comienza a familiarizarse con los problemas de la gestión y organización del espacio social para fines estrictamente económico-políticos ${ }^{4}$, pasando a conformar un elemento esencial para la biopolítica estatal. De acuerdo a esto, lo urbano (entiéndase, por un lado, la organización y segregación territorial y, por otro, la supremacía de intercambios y flujos mercantiles) podría ser comprendido como el resultado del proceso ininterrumpido de urbanización de la Tierra ${ }^{5}$ que se inicia con la modernidad y continúa hasta nuestros días. El estudio y análisis de este proceso convoca necesariamente distintas perspectivas: arte, arquitectura, sociología y antropología urbana, las que tienen mucho que aportar, pues a través del colosal despliegue de la urbanización acontece la erosión de la matriz política de la ciudad, cuyo símbolo preclaro es la explosión, en cada rincón del planeta, del rostro ubicuo de un déspota6: el ciudadano-consumidor, protegido y vigilado por la policía que vela por la normalidad en el intercambio de flujos. En otras palabras, la homogeneización creciente que conlleva el desarrollo de una plataforma urbana que no conoce límites, no puede darse sin el concurso de una policía o, más bien, de una biopolítica que empapa discursos y prácticas entre los que destacan la intervención de la arquitectura y el urbanismo, que hacen de la ciudad un gran mercado y del ciudadano un consumidor pasivo ${ }^{7}$. De este modo, uno de los legados inesperados de la obra de Le Corbusier y de las reuniones en los Congresos de Arquitectura Moderna (CIAM) es, tal vez, haber profundizado en la aniquilación de la vida activa del ciudadano, iniciada en los tratados de policía, pero afinada, más tarde, en el trabajo conjunto del saber social positivista y el dominio creciente de la esfera económica en todas las manifestaciones de la vida, con la justificación de responder con urgencia a las necesidades de la población de consumidores pasivos ${ }^{8}$.

La crítica situacionista al urbanismo moderno es explícita en el "Programa elemental de la oficina de urbanismo unitario" (1961)9. El escrito ofrecerá un diagnóstico del montaje preparado por los "falsos especialistas de la ciudad" y propondrá los lineamientos que permitirían crear un "verdadero" urbanismo, tras revertir los efectos resultantes del control del espacio y del condicionamiento de la vida cotidiana en la metrópolis moderna ${ }^{10}$. En el presente artículo se propone interpretar retrospectivamente el Programa elemental, que ataca las bases arquitectónicas y urbanísticas de la domesticación de la vida social, desde los textos previos "Introducción a una crítica de la geografía urbana" (1955) y "Otra ciudad para otra vida" (1959), ya que a partir de ambos se esbozan los primeros pasos de una crítica de lo urbano. Esta crítica se halla marcada por la idea de "repolitizar" la arquitectura de la ciudad y convertir el decorado urbano en un verdadero espacio común, capacitado para acoger todas las razas del mundo, utilizando como instrumento megaestructuras desmontables preparadas para dar forma a "atmósferas" sociales, que buscan superar los acostumbrados "lugares" de la arquitectura tradicional (Constant y Debord). A partir de esta discusión, se presenta el ideario de Constant Nieuwenhuys representado por su proyecto New Babylon"1, utopía arquitectónica realizada en diversos soportes plásticos que pareciera ser el único intento "concreto" para dar viabilidad práctica al planteamiento teórico situacionista ${ }^{12}$. 


\section{La crítica de lo urbano: una utopía po- sible}

En pleno apogeo económico de Europa, desde mediados de los años cincuenta los situacionistas advierten sobre la necesidad de reconvertir los ambientes metropolitanos de uso colectivo. Para ellos el espacio social se encuentra degradado por la acción conjunta del urbanismo y el mercado para cumplir el rol exclusivo de territorio reservado para el consumo pasivo' ${ }^{13}$. El ojo de los situacionistas está puesto en la nueva faceta espectacular que emerge en la vida pública, en tanto falsea la historia y la memoria del espacio social. Paradójicamente, al final de la historia de la ciudad, en su propia ruina, la metrópolis se dibuja como un escenario atemporal en que el genius loci es doblegado por la necesidad de potenciar la circulación de hombres y mercancías a costa de diluir todo espacio de relación y conflicto social. No es de sorprender, entonces, que Lewis Mumford, sostuviese que Le Corbusier había trabajado como un buldócer, destruyendo el pasado, cortando los lazos que unían el lugar a su memoria y neutralizando las capas de sedimentación histórica que la constituía como espacio social'14. En este escenario, las críticas e intervenciones situacionistas propondrán un nuevo imaginario contra la imagen de mundo esculpida por el urbanismo a partir de una planificación del territorio que ha favorecido casi exclusivamente a los intereses económicos del capitalismo's.

Si retrocedemos hasta los inicios del situacionismo se advierte que el "I Congreso mundial de artistas libres", realizado en Alba, Italia, en 1956, resulta una experiencia crucial para quienes más tarde fundarán la Internacional Situacionista, especialmente para Constant ${ }^{16}$. Gil L. Wolman, en nombre de la Internacional Letrista, exclamaba: "si los templos [...] han sido un medio para trasmitir la representación de una colectividad histórica, nos incumbe, a nosotros, erigir los monumentos que expresen, a través de nuestro ateísmo, los nuevos valores de una nueva manera de vivir, cuya victoria es innegable." ${ }^{17}$. Años más tarde, en el empeño de construir un urbanismo crítico que se hace eco de estas palabras, los miembros de la IS trabajarán en la búsqueda de alternativas ante la anestesiada y segregada vida cotidiana metropolitana. El objetivo consiste en convertir el terri- torio en un laboratorio de experiencias orientado a diagnosticar estrategias de dominación y entrever tácticas de subversión, a romper, en definitiva, con la naturalización de los límites que impone el mercado al espacio social: "la estructura urbana actual es el instrumento más utilizado por las clases dominantes para acrecentar su dominación, controlando la gestión del espacio y aumentando la sedimentación socioeconómica" ${ }^{18}$. Más concretamente, en su exploración "vital" del fenómeno urbano contemporáneo, la IS confronta el condicionamiento de la vida social que instalan aislamiento y consumismo en el repertorio de hábitos de los seres urbanos como conquista de la vida moderna ${ }^{19}$. Asimismo, combate enérgicamente la arquitectura que ha creado ese decorado ${ }^{20}$ y proyecta una "utopía posible" como alternativa a los cementerios de hormigón armado donde los sujetos viven actualmente alienados ${ }^{21}$.

En un punto esencial coincidirán la mirada de los situacionistas y Henri Lefebvre con la de los funcionarios del urbanismo, y es que, para todos, el futuro es fundamentalmente urbano. Sin embargo, para los situacionistas, el urbanismo que gestiona el condicionamiento social, según los intereses del mercado capitalista22, debe ser superado por un "urbanismo unitario", que resulta de la confluencia de las artes y técnicas puestas en juego para la creación de un medio susceptible de ser transformado a voluntad por los ciudadanos ${ }^{23}$ (sintonizando de ese modo con lo que Lefebvre había planteado como "derecho de ciudad" ${ }^{24}$. De acuerdo al estudio de Wigley, la transformación de la atmósfera urbana deviene la base de la acción política para los situacionistas ${ }^{25}$, pues no se trata de reinventar la ciudad, por un lado, y de pensar la política, por otro, sino de acabar con aquello que justifica su distanciamiento: la separación. En otras palabras, lo que se busca es reintroducir en el espacio urbano la dimensión afectiva de lo común, expulsada de la metrópolis que instala el aislamiento como condición de las relaciones sociales. En ese marco es que se apunta contra el urbanismo moderno como un enemigo de la experiencia política del territorio, porque en su afán de controlar los flujos ha contribuido a la elisión del sentido político y cooperativo de la vida social en la ciudad. Lo elidido en la planificación que confluye en segregación espacial, es justamente la posibilidad de que individuos 
diversos puedan tejer entre sí relaciones desde su propia heterogeneidad. Al verse aislados en el espacio familiar, los habitantes de las grandes ciudades no llegan a ser otra cosa que una "masa de extraños alienados" 26 : alienados en el trabajo y en el tiempo libre, ya que el ocio se revela como uno de los principales instrumentos para servir a los objetivos de la dominación y la acumulación ${ }^{27}$. Pese a este lúgubre diagnóstico, lo que muestran los situacionistas (exaltando tal vez no sólo la raigambre política, sino ética del derecho de ciudad) es que el porvenir es irrefutablemente urbano: en la fragmentada vida urbana yace, para todos, la posibilidad latente de romper la alienación apropiándose de las condiciones en que se produce lo social como separación.

\section{Acerca del "Programa elemental de la oficina de urbanismo unitario"}

El Programa elemental de Attila Kotányi y Raoul Vaneigem publicado en 1961 advierte que el urbanismo moderno, supuesto como un saber "objetivo", ha emplazado en el espacio de las grandes ciudades un modelo de experiencia y conducta acorde únicamente a los intereses domesticadores del capitalismo ${ }^{28}$. Cimentando el aislamiento de los habitantes de las ciudades gracias a la prioridad que recae en la circulación, el urbanismo habría logrado erradicar con éxito un aspecto esencial de la ciudad: el azar y la heterogeneidad, fundamentales para la experiencia viva de sus espacios, poniendo en su lugar el espectáculo, despojándola de su aliento político ${ }^{29}$. En suma, de acuerdo a esta postura, el urbanismo habría entronizado la privatización de la experiencia metropolitana ${ }^{30}$, pues, aislados en nidos familiares, los individuos alcanzarían un nivel óptimo de incompetencia social, aprendiendo a concebir cualquier relación externa como un servicio ${ }^{31}$. Teniendo esto a la vista, se comprende la amplitud del siguiente juicio acerca del vínculo de arquitectura y urbanismo: el urbanismo no existe, al contrario, es pura ideología espectacular. La arquitectura, por su parte, existe, pero como mera producción investida de ideología que, diríamos, se ha puesto al servicio de las necesidades (creadas) por el capitalismo, sin considerar a los ciudadanos, despojados de su aliento político, que solo pueden participar alienadamente del espectáculo de la ciudad ${ }^{32}$. La circulación, que es la organización del aislamiento, contribuye netamente a crear, entonces, como lo opuesto al encuentro y a la participación ciudadana, una falsa participación en lo social, la participación en la propia alienación mediada por el espectáculo, lo cual se hace manifiesto en el gradual acceso al confort y al movimiento de los habitantes de las ciudades: "no se habita en un barrio de una ciudad, sino en el poder" ${ }^{33}$. Se habita, pues, en un poder que segrega, que destina (o condiciona) a cada individuo o grupo al lugar que le corresponde en el entramado de relaciones socioeconómicas, dotándole de una determinada posibilidad de movimiento, según la incidencia de su existencia en el reforzamiento y crecimiento de ese mismo poder, que se blinda contra toda posible amenaza de desestabilización ${ }^{34}$. Estas ideas parecen anunciar las tesis de Debord de La sociedad del espectáculo (1967). En efecto, Debord afirmará que el espectáculo es el reino de la separación o "la separación es el alfa y omega del espectáculo" ${ }^{35}$. En otras palabras, en el mundo actual los individuos solo pueden unirse en tanto se hallan separados ${ }^{36}$, y dicha separación ha sido esencialmente afinada por el urbanismo ${ }^{37}$ : "El urbanismo es la conquista del entorno natural y humano por parte de un capitalismo que, al desarrollarse según la lógica de la dominación absoluta puede y debe reconstruir la totalidad del espacio como su propio decorado" ${ }^{38}$. En suma, el urbanismo ha contribuido a la disolución de la heterogeneidad ciudadana, y, con ello, a la disolución de la ciudad, su historia y la memoria de los conflictos que le fueron inherentes. La ciudad domada se ha erigido como el dispositivo que pretende anular toda acción creadora de espacios de relación, conflicto y encuentro fuera del que impone el espacio del consumo y la producción.

En ese contexto de crisis de la vida social en su conjunto, y como un arma para combatir expresamente el aislamiento pasivo, se presenta el concepto de "urbanismo unitario". Frente a las ciudades dormitorio, definidas como "jardines infantiles coloreados y ventilados" ${ }^{\prime 39}$, el urbanismo unitario pretende contribuir al levantamiento, a la insurrección de las masas metropolitanas contra su entorno y los modelos de conducta que representa, estableciendo las bases de una vida experimental que permitirá la "reunión de creadores 
de su propia vida." "40. Esta "vida experimental" no pretende un retorno al mundo precapitalista de la ciudad antigua, contrariamente, se entiende como la búsqueda colectiva de un más allá del "espacio ocupado por el enemigo que ha domesticado el planeta" para realización de todos. En efecto, al combatir el aislamiento, gracias a la "apropiación del condicionamiento por todos", se liberaría la energía contenida en la vida cotidiana petrificada que impone el capitalismo a través del urbanismo. Este intento colectivo de liberar la potencia de la vida cotidiana, apropiándose de los medios para la producción del espacio común, renueva tanto el sentido de la acción como de la teoría política, cuyo objeto concierne a la ponderación del "valor de uso" de la vida", para terminar constituyéndose en el primer estallido de la guerra al "espectáculo" que remece y despierta a Europa y el mundo de su aletargamiento a pocos años de escritos estos textos, cuya pertinencia parece innegable tras mayo del $68^{42}$.

\section{3. "Introducción a una crítica de la geo- grafía urbana"}

La sociedad del espectáculo sostiene que la homogeneidad de las ciudades, efecto de la intensa labor de la industria y estandarización de la vivienda, ha dado lugar a uno de las principales encrucijadas socio-políticas de nuestra época: la "separación espectacular". Esto puede ser comprendido del siguiente modo, a saber: si el destino del habitar colectivo, convertido en uno de los objetivos por el urbanismo, consiste en suprimir la posibilidad de construcción social de comunidad (impidiendo a toda costa que la vecindad y el roce asociado a compartir un espacio engendre conflicto, y proyectando las partes de la ciudad como un todo orgánico) el espectáculo constituye ante todo la separación consentida, la voluntad de participar, al mismo tiempo, del aislamiento y del proceso técnico mediante el cual, paradójicamente, se engendra la propia sociedad del espectáculo como familia de consumidores que comparten un mundo: el de la mercancía. Varios años antes, Guy Debord, en "Introducción a una crítica de la geografía urbana" (1955), publicado en la revista Les lèvres nues, afianzaba la propuesta del nuevo urbanismo en la necesidad de tomar por objeto la intervención colectiva en la vida urbana "depotenciada" por la planificación territorial. En tanto práctica de saber, la crítica de la Introducción antes que una teoría define una actitud, un gesto que desbordaba el ámbito de lo meramente reflexivo y descriptivo para devenir "análisis experimental", que acabará sirviendo de sustento para la idea de "vida experimental" que será reivindicada en el Programa elemental. El análisis experimental, que anuncia ya lo que en el urbanismo unitario será una consigna, apunta a crear colectivamente una nueva forma de vida en lo que se presenta hoy como un destino forzado, exhortando a la apropiación de los medios y materiales disponibles para gestar colectivamente un nuevo territorio de afectos.

Para los situacionistas, así como para Lefebvre, Le Corbusier (declarado defensor de Haussmann y su trabajo de demolición del viejo y "enfermo" París $\left.{ }^{43}\right)$ habría dictaminado el sentido del urbanismo moderno en su vinculación con el poder y el mercado capitalista: instalar el aislamiento colectivo a través del cálculo razonado de las distancias, la separación concreta, que sería la encargada de salvaguardar la justa relación y circulación de hombres y mercancías y, por esa vía, de la propia reproducción del mismo sistema. Para toda esta vertiente crítica, el desarrollo del urbanismo funcionalista es el autor material de todo un sistema de divisiones que se instala como reino de lo homogéneo y que se impone a los seres urbanos para conjurar la emergencia de situaciones, de nuevas formas de habitar. En su perspectiva, la espacialidad que instala este urbanismo no trabaja como condición de la vida social, sino que dispone los ejes en el que se desarrolla el condicionamiento de la vida colectiva con el único fin de satisfacer las necesidades de la llamada "vida moderna", que conjuga perfectamente productividad y dispendio para reforzar el orden dominante.

El urbanismo en boga instala el reino de lo homogéneo, de lo regular y se convierte a los ojos de los situacionistas en lo que hay que desarreglar y combatir a toda costa a partir de una nuevo método experimental, que emerge como una amalgama del juego, la "deriva", y de una nueva forma de conocimiento, la "psicogeografía". La dérive, concebida por los letristas en los años previos a la formación la Internacional 
Situacionista, constituye el acto, el gesto, la experiencia efímera de trazar trayectos exóticos o poco habituales en el entramado de lugares y funciones de la ciudad ordenada y jerarquizada ${ }^{44}$. La psicogeografía, por su parte, se presenta como el instrumento encargado de medir los efectos del medio geográfico sobre el comportamiento afectivo de los individuos, con el fin de crear, a partir de su carácter dislocador, las condiciones para una nueva vida.

En una línea que dialoga aunque termina por alejarse de la vanguardia situacionista, Henri Lefebvre define el urbanismo por venir, a partir del derecho ciudadano a transformar el espacio habitado45, razón por la cual acabará más cerca de la atmósfera de libertad que instala el proyecto New Babylon de Constant ${ }^{46}$ que de Debord y sus seguidores. No obstante, en un punto coinciden sus perspectivas: el urbanismo venidero, combatiendo el empobrecimiento del pathos de la ciudad, deberá ocuparse de la construcción de aquello que enriquece la vida anímica, de romper el condicionamiento que embrutece; en otras palabras, el nuevo urbanismo será el encargado de reintroducir lo imprevisible, el azar, el juego, en el reino de lo previsto y planificado, torciendo el rumbo que había cifrado el urbanismo para la urbe del siglo $X X$, perpetuando subrepticiamente el modelo de ciudad y sociedad de occidente.

\section{Constant: "otra ciudad para otra vida"}

"La ciudad ideal de Urbino", atribuida entre otros a la escuela de Piero de la Francesca, Luciano Laurana y Francesco di Giorgio Martini, es célebre por transmitir por primera vez una instantánea de la eternidad, gracias a la técnica perfecta que la sostiene. En el cuadro, el ojo penetra el espacio sin ningún efecto retórico, sin resistencia, todo es claridad pues los edificios hallan una armonía perfecta en las líneas que se cruzan y que dividen el cuadro en partes iguales: desde el centro a su periferia el cuadro entrega una medida de la ciudad y del universo como un juicio irrevocable, como una sentencia cósmica que instala el orden de una vez por todas. Milagrosamente, la nueva técnica devuelve o restaura la medida arrebatada al proyecto ejecutado y, por lo mismo, devorado por la injusticia de la ciudad "real". En otras palabras, la pintura se vuelve la "verdad" de la arquitectura, pues ésta se corrompe en el momento en que transita el umbral que define la distancia entre el diseño y el hecho arquitectónico. En dicho tránsito, podríamos suponer, la arquitectura queda atada a los vaivenes erráticos de la vida de los hombres. En cambio, en el cuadro la ciudad permanece intacta, puro espacio ideal de la ciudad perfecta. Lo fundamental: el cuadro no imita un modelo, sino que se erige a sí mismo como la realización sensible del número, a través del perfecto reparto de las cosas y del propio espacio. No obstante, es fácil reconocer que en ese espacio perfecto, en esa extensión mensurada y rotunda, los hombres han desaparecido, han perdido su lugar, llevándose consigo hasta su pálida sombra. Desolador. Todo es claro y evidente... porque en ese panorama los hombres están ausentes. El espacio de la città ideale representa la ciudad vacía, sin vida ni huella humana, entendiendo que la desaparición de los seres humanos (o su propia negación) ha sido el precio de alcanzar la perspectiva celeste. Un precio justo, pareciera, pues de esa manera se evita el riesgo de ver renacer la confusión en el seno de la ciudad. La representación de la sola extensión del espacio, en suma, sirve aquí para conjurar la confusión que se asocia a la existencia, a la ocupación y dislocación del orden. Así, la imagen perfecta que hace posible la perspectiva, borrando toda huella humana, deviene la única diáfana e intelectual.

Desde los años sesentas numerosos artistas y arquitectos habrán bebido de la efervescencia situacionista, ofreciendo la imagen de otro mundo anhelado para la vida colectiva, fuera de los causes de la modernidad capitalista. New Babylon, así devino el prototipo de la nueva utopía urbana ${ }^{47}$. Introducida en 1958, el plan que mira hacia la colosal ciudad de oriente, busca inspirar la imagen de otra realidad social antes que erigir un modelo prescriptivo ${ }^{48}$, y para esto dispone de la unión de elementos dispares: maquetas, bocetos y textos se agolpan para trazar el esquema de una torre horizontal, concebida para transformarse según la voluntad de los habitantes y recorrer los límites de la tierra. Las distintas variaciones del trabajo de Constant no constituyen una metáfora de la mítica ciudad de la confusión, sino que se ofrecen como repetición de su soberbia efímera, que cobra vida más que para satisfacer necesida- 
des, para colmar los deseos de sus habitantes. Por ello, cabe apreciar que la Nueva Babilonia, monumento al juego y la espontaneidad, proyecta una contraimagen de la ciudad ideal en occidente, marcada por la exigencia de orden y control del factor humano.

En el texto de 1959, "Otra ciudad para otra vida", Constant profundiza en la crítica al estado calamitoso de las ciudades desarrolladas y esboza para su transformación una imagen concreta de la nueva arquitectura y del nuevo urbanismo, anunciado cuatro años antes por Debord en la Introducción. En Otra ciudad, legado de su relación con Debord, se insiste una vez más en los costos sociales de la acción del movimiento moderno: el mundo "arquitecturado" por los urbanistas ha desatendido completamente lo que enriquece las relaciones sociales, partiendo de una concepción encapsulada en la familia, el trabajo y el ocio, se ha negado a trascender el horizonte de las necesidades individuales para concentrarse únicamente en resolver los problemas que atañen al creciente aumento de la población en las áreas metropolitanas, la circulación vehicular y el confort de las viviendas de las clases medias. Por ello a sus ojos la construcción acelerada de ciudades se asemeja a la construcción de cementerios de hormigón armado: la homogeneidad urbana asesina la creatividad de las masas de ciudadanos sin ciudad, por falta de imaginación de sus planificadores. No obstante, para Constant, este mismo tiempo de penuria es también el tiempo en que despierta una nueva era, presta a crear la imagen de una vida más dichosa y de un urbanismo unitario; el tiempo, en suma, en que el urbanismo será concebido para el placer de todos, es decir, para el placer socialmente experimentable, allende la ciudad verde y sus jardines infantiles coloreados y ventilados, bajo el imperativo de gestar las condiciones para una relación estrecha, física y afectiva entre los sujetos, y de estos con el entorno urbano, rompiendo con la alienación y el aislamiento de la ciudad actual.

\section{New Babylon: la utopía posible}

Constant, tras su partida de la IS ${ }^{50}$, se consagra íntegramente al diseño y teorización de la ciudad "nómade". Con New Babylon se proyecta la visión de un nuevo espacio social, una "uto- pía posible", que, según Careri, representa una "alternativa para la vida cotidiana y posibilidad concreta de habitar el mundo." ${ }^{51}$. El sentido de esa "utopía posible" es, pues, de suma importancia, dado que en él se dibuja el contrapunto de la carga utópica que concentra el Programa elemental. New Babylon no constituye una quimera, pues sólo falta proveer las condiciones para su existencia real52. Trabajar para su existencia futura implica sentar sus bases aquí y ahora en un referente histórico, el nomadismo, sepultado por la sedentarización progresiva de la sociedad ${ }^{53}$, apropiándose de las tecnologías disponibles para la producción de un "nuevo hombre" y de una "nueva sociedad", sin fronteras, ni domicilio fijo, liberando la vida de la tiranía de la necesidad para abrirla a los deseos de los hombres ${ }^{54}$.

Para Constant, New Babylon es la visión político-arquitectónica de un mundo habitado por multitudes libremente creadoras ${ }^{55}$, que superan la constricción del domicilio fijo y el trabajo alienado para liberar el tiempo del ritmo pulsado que ambos le imponen. Lewis Mumford, avanza en esta línea, confiando esa superación al automatismo tecnológico: en el instante en que se socialicen los aportes de la mecanización, el ritual del ocio reemplazará al ritual del trabajo "y el mismo trabajo se tornará un juego" 56 .

Constant continúa por otros medios las tesis del urbanismo situacionista, sin abandonar el leitmotiv de la crítica. Es más, para interpretes como Heynen, New Babylon no es otra cosa que la proyección de una sociedad que ha realizado el urbanismo unitario ${ }^{57}$. Para Careri, por su parte, el proyecto ofrece concretamente un modelo alternativo al capitalismo, su filosofía y sus elementos constitutivos (sistema de producción, acumulación de bienes y propiedad privada), introduciendo una nueva concepción del tiempo, un nuevo uso del espacio y, así, una nueva experiencia de vida, que busca ir más allá de aquello que se impone como social y políticamente deseable ${ }^{58}$ en el capitalismo. En último término, la automatización que supone la vida libre del proyecto de Constant, busca impedir que los hombres continúen al servicio de la técnica y la producción en los términos que supone este reino de los individuos aislados. El uso racional de la máquina, para Mumford, no promete la elimina- 
ción del trabajo, sino del trabajo "servil"59, sólo por ese medio el ciudadano pasivo puede llegar a convertirse en el homo ludens, a cuya creatividad social se subordina inclusive el trabajo.

Constant proyecta una megaestructura, un colosal interior ramificado que busca reunir libremente todas las razas y culturas para dislocar la hegemonía histórica del régimen sedentario, cuya modelo lo constituye el funcionalismo moderno y la Carta de Atenas ${ }^{60}$, que no sólo otorga una función única a cada espacio61, sino que condiciona al habitante para ocupar una única atmósfera ${ }^{62}$. Contra este modelo el artista concibe una megaestructura desmontable para componer en último término un complejo y ramificado espacio público ${ }^{63}$. Tal configuración, sin embargo, difiere de lo que se comprende bajo el vocablo "ciudad", pues, "la ciudad es una forma de urbanización característica de la sociedad utilitarista. Es el lugar donde reside una población estable, arraigada a un modo de vida particular" ${ }_{64}$. New Babylon, al contrario, asume que una nueva sociedad de hombres libres, creadores de sí mismos, no puede darse bajo los mismos cánones y condiciones que había impuesto la arquitectura del sedentarismo. Recordemos que no sólo Constant, sino que todos los situacionistas pretendían en algún modo ser arquitectos en la construcción de situaciones concretas en el contexto de la ciudad, situaciones carentes de la solidez e inmovilidad de las construcciones edilicias tradicionales ${ }^{65}$.

La unidad básica de la megaestructura es el "sector", cuyo tamaño dependerá de la trama de las relaciones sociales que con el tiempo abandonarán sus formas habituales, marcadas por los monótonos ritmos del trabajo y la vida familiar, para dar lugar a formas de relación menos limitantes y, por tanto, más joviales y azarosas. En cuanto a su diseño, el sector es una macroestructura, cuyo principal valor es estar dispuesto para la construcción, transformación y reconstrucción permanente, según la voluntad de sus usuarios. Esta macroestructura puede encontrarse sostenida por pilares o estar suspendida de uno o varios mástiles o ser autoportante, dependiendo de las condiciones geográficas. El sector está ensamblado sin un orden definitivo, es decir, está al servicio de la esencia lúdica del habitante de New Babylon, que puede desear e incidir concretamente en la transformación de su interior. Para ello, es necesario que los elementos de la arquitectura móvil (como paredes, suelos, escaleras, mangas de ventilación, puentes, etc.) puedan, primero, ser desplazados de un lugar otro y, segundo, puedan montarse y desmontarse fácilmente, permitiendo la reutilización. En cuanto a su imagen, el sector es un esqueleto horizontal, elevado unos veinte o treinta metros del suelo, que alcanza unas veinte hectáreas de terreno. Contiene un espacio interior en el que se agrupan los "núcleos" que albergan los centros técnicos, los centros de aprovisionamiento y las habitaciones individuales. En estos núcleos, asimismo, se proyectan la construcción de bibliotecas, centros de investigación científica, escuelas y equipamientos de salud. Una parte del sector está compuesta de los núcleos, la otra, la más importante según Constant, está orientada a convertirse en espacio social66, es decir, en lugar de encuentro, porque "la espacialidad es social" 67 . Los núcleos deberían favorecer el encuentro y contacto entre los individuos, allende los límites que impone la relación sedentaria casa-ciudad, promoviendo especialmente el desarraigo de quienes: "... se desplazan errantes a través de los sectores de New Babylon en busca de experiencias nuevas, de ambientes aún desconocidos. Sin la pasividad de turistas, sino plenamente conscientes del poder que tienen de actuar sobre el mundo, de transformarlo, de recrearlo." ${ }^{68}$. Esta descripción condensa la propuesta exploratoria y experimental del proyecto social de Constant: el diseño ofrece los equipamientos colectivos necesarios para atender una población fluctuante, pero todo el escenario en que se desarrolla la vida social se asienta en la movilidad y en la transformación. En una palabra, en New Babylon, los individuos errantes se lanzan al encuentro de nuevas experiencias en un mundo que ellos mismos arquitecturan en su transitar.

\section{Para una crítica de la espacialidad mo- derna}

Hacia finales de los años cincuenta, las discrepancias con los principios de la arquitectura "sedentaria" no sólo provenían de quienes configuraron la Internacional Situacionista ${ }^{69}$. Uno de los aportes desde la arquitectura al estudio y comprensión de la arquitectura de estructuras 
desmontables, junto con Archigram, proviene del arquitecto Yona Friedman, quien será el autor de "Arquitectura móvil", documento que celebra la creación de GEAM (Groupe d'Études $d^{\prime}$ Architecture Mobile) en 1958. Friedman asistió a la penúltima reunión de CIAM, realizada en Dubrovnik el año 1956, para presentar una primera versión del manifiesto, que criticaba el tratamiento ambiguo de nociones como movilidad o desarrollo, ya que impedía su real valoración ${ }^{70}$.

Friedman proyecta la creación de viviendas individuales a partir de prototipos industriales diferentes que se conectan a una estructura soportante y a servicios que la red suministra. Estos prototipos son concebidos como cápsulas prefabricadas, desmontables, transformables y ensamblables a voluntad por los usuarios en los esqueletos estructurales o megaestructura que descansa sobre pilones distanciados entre sí, que se posan sobre la ciudad "real" buena medida, se sirve de la arquitectura corbusiana, dejando en las manos de los usuarios el destino final de la obra, mostrando que los materiales de que dispone la arquitectura no agotan el hecho arquitectural, pues este dependerá de la manera en que estos materiales son agenciados.

Todo constructo espacial, en suma, se postula como el resultado de la colaboración de especialistas y usuarios ${ }^{72}$. Las diferencias entre la concepción rupturista de la arquitectura de Friedman y la propuesta crítica de Constant son, no obstante, insoslayables ${ }^{73}$. Para Friedman, la arquitectura no constituye una "política", sino un saber ocupado en resolver problemas urbanos (vivienda, circulación de habitantes y mercancías), acentuando que la responsabilidad recae finalmente en los usuarios liberados de las limitaciones de la arquitectura tradicional74. La acción de los usuarios en la escala urbana, empero, sería bastante acota$\mathrm{da}$, pues se fomentaría únicamente su rol en el co-diseño de espacios privados ${ }^{75}$. No obstante, Friedman, que ponía la megaestructura al servicio de la sociedad hiperdesarrollada del capitalismo, como un vidente avizoraba el éxito de las estructuras autoportantes en los centros comerciales, verdaderos templos del consumismo, esparcidos por doquier, y que pueden ser recorridos por miles de personas diariamente. Nada nuevo bajo el sol, si se quiere, pues ya la arquitectura y la ingeniería decimonónica aparecía como el instrumento privilegiado para proveer de un nuevo fundamento para lo urbano que se abría paso en las ruinas de la ciudad histórica: en pleno desarrollo del capitalismo, el montaje de acero y vidrio encarna la esperanza de erigir el verdadero "lugar común": espacios de ocio, como galerías comerciales, y espacios de trabajo, como las fábricas y ciudades obreras. Ambos tipos de espacios, que se articulan bajo el principio de la movilidad y la edificación rápida, reflejarán la conciencia de una época que se representa así misma como "transparente"76.

Contra el peso de esa historia, Constant confía en que la arquitectura de megainteriores puede todavía desviarse y servir a otros fines totalmente ajenos a los intereses del consumo y el trabajo alienado. La creación de atmósferas y la variabilidad de los ambientes en New Babylon quiere representar las condiciones básicas para una nueva vida, acorde a los principios de la nueva arquitectura que supone el abandono de la antigua forma urbana (sedentaria) y, con ello, de las costumbres que le son esenciales (familia, trabajo, propiedad, etc.) para el surgimiento de una nueva sociedad y un nuevo hombre, el homo ludens. Constant, en clara disputa con el encapsulamiento de la vida social y la homogeneidad del ritmo cotidiano del ocio y el trabajo en el capitalismo, traza un proyecto más allá del cual todavía pueden advertirse los contornos de una nueva realidad posible.

La propuesta del urbanismo situacionista ampliada por Constant en New Babylon expone el diagrama de un mundo alterativo, que replantea la manera y el objeto de concebir el "espacio común", haciendo frente directamente a los pilares en los que se asienta la interesada sociedad burguesa: trabajo, familia, propiedad privada y Estado. Implica, entonces, una crítica paralela a la economía capitalista y a la filosofía ilustrada, ya que ambas convergen en el desarrollo y puesta a punto de la forma social que acaba con la reducción del ciudadano a trabajador y solitario consumidor pasivo. Las palabras de Adorno convienen para ilustrar este punto: "La propiedad fija difiere del desorden nómada al que toda norma se enfrenta; ser bueno y tener bienes se coinciden desde el principio. El bueno es el que se domina a sí mismo igual que domina su posesión: 
su autonomía es un trasunto de la disposición material" 77 . El pensamiento nómade de Constant ha tenido que enfrentarse a esa verdad del individuo ilustrado, verdad que radica en el grado de autonomía, es decir, de la separación que experimenta con respecto a sus necesidades, en suma, a su capacidad de "liquidez" 78.

Frente a tal modelo de pensamiento y costumbres, que parece incuestionable en nuestras democracias, termina por oponerse el imaginario de Constant, imaginario que contesta las propias raíces del pensamiento ilustrado. De modo que en toda agitación radical actual en la esfera de la ciudadanía, que apunte contra los fundamentos de la comprensión pasiva de la vida ciudadana, parece observarse los ecos de la diatriba materialista de Constant, quien desde la oposición al trabajo asalariado y la propiedad privada combatía por una real incidencia en la construcción social del territorio y, en esa medida, por la transformación definitiva de la masa anónima en multitud libremente deseante.

\section{Conclusión}

Racionalizar los flujos que sustentan y que, al mismo tiempo, perturban las grandes ciudades europeas había sido el rol fundamental de la policía, que debía enfrentar y, paralelamente, aprovechar la crisis en que se hallaban en pleno apogeo del mundo industrial europeo, cuidando de implantar correctamente un orden dinámico en el territorio que hereda sus funciones. En el siglo XX, el urbanismo, siguiendo la estela de los principios de la policía, consciente o inconscientemente, se consagrará a la tarea de conducir los destinos de un mundo hiperdesarrollado, que sienta sus bases en la disociación del nudo social de la ciudad.

Para la Internacional Situacionista, el condicionamiento de la vida urbana, que había escrito el destino de las masas metropolitanas desde los orígenes del capitalismo, sólo era combatible, al menos en un primer momento, poniendo en práctica una "utopía posible" (un pensamiento crítico para la acción). Enfrentándose al aislamiento colectivo y su ethos "privativista", el fin de esta utopía era la apropiación del condicio- namiento existente, para potenciar ciudadanos transformadores de sus espacios.

El resultado de la propuesta urbanística del grupo de Guy Debord es el "urbanismo unitario", ideario para la creación de una atmósfera arquitecturada por los propios habitantes. El fin, concretamente, era romper el condicionamiento y apropiarse de los materiales disponibles para servir a los deseos comunes, fomentando aquello que enriquece la vida anímica del colectivo. Influenciado indiscutiblemente por Debord, Constant presenta New Babylon, imaginario o concepto de ciudad nómade, elaborado a partir del montaje de dibujos, pinturas diseños, maquetas y collages que aspiran a dislocar la hegemonía del funcionalismo moderno y, con ello, de la más acabada imagen de la sociedad que impone occidente. La imaginería nómade de la megaestructura desmontable de Constant traduce una política cuyo propósito es la irrupción de un nuevo espacio común y una nueva sociedad, contribuyendo a repensar las condiciones de otra arquitectura social. Para otros que indagaban en el uso de la arquitectura móvil, como Yona Friedman, las megaestructuras, concebidas como respuestas a problemas "reales", sólo devienen instrumentos útiles para optimizar los recursos de la sociedad existente. En ese sentido, pese a su innegable aspecto vanguardista, la Nueva Babilonia resulta diferente y hasta opuesta a las obras que idealizaron el entorno tecnificado. La perspectiva nómade de Constant no solo constituye el deseo de un espacio social por venir, sino también la fórmula de un imaginario que confronta, en el presente inmediato, el dispositivo naturalizado de poder y el espectáculo que funda la "autonomía" y el "bien común" en la separación y, en último término, en la defensa de la propiedad privada; en la historia, la obra de Constant, en tanto modelo opuesto a la "ciudad ideal", confronta una larga tradición teórica en arquitectura, política y filosofía ilustrada que basa la organización de la ciudad y de la sociedad en el reparto jerárquico de lugares y funciones para anticiparse al errar humano y evitar que la espontaneidad, germen del desorden, introduzca el caos en el espacio habitado. 
NOTAS

${ }^{1}$ Para Benjamin, la presentación estética de dicho acontecimiento corresponde a la imagen sin interior del individuo en el ajetreado transitar urbano: expuesto a la contemplación de los otros, el anónimo paseante reluce en público mientras ve relucir a otros en un infinito juego de espejos. No obstante, esa vida reflejada en el espacio público, en la miríada de paseantes, es una pura aparición inesencial, mero brillo sin alma, pues individualismo y soledad es el precio que ha pagado la ambigua realidad que rodea la conquista de las libertades burguesas.

${ }^{2}$ Es Ildefonso Cerdá en Teoría general de la urbanización (1867), quien crea el neologismo "urbe" para referirse a aquello que anima la ciudad, algo que la palabra "ciudad" ya no puede contener (A. Cavalletti, Mitología de la seguridad. La ciudad biopolítica, Buenos Aires, Adriana Hidalgo Editora, 2010, p. 32)

${ }^{3}$ Michel Foucault es quien precisa que gran parte de las funciones que asume el urbanismo estaban a cargo de la policía desde el siglo XVI. Esta se preocupaba de la "conservación", de la "bondad" y de los "encantos" de la vida, en suma, se encargaba del "vivir" y del "vivir bien" (M. Foucault, Seguridad, territorio y población. Curso en el Collège de France 1977-1978, Buenos Aires, FCE, 2006, p. 380).

${ }^{4} \mathrm{M}$. Foucault, "El ojo del poder", en Bentham Jeremy, El panóptico, Buenos Aires, La piqueta, pp. 11-12

5 Th. Paquot, L'urbanisation c'est notre affaire!, Nantes, L'Atalante, 2010, p. 28.

${ }^{6} \mathrm{M}$. Bonta, J. Proveti, Deleuze and Geophilosophy. A guide and glossary, Edinburgh, Edinburgh University Press, 2004, p. 103. Avala esta tesis Massimo Cacciari al definir la Metrópolis por dos procesos íntimamente ligados: el de racionalización de las relaciones sociales, que sigue a la racionalización de las formas de producción (M. Cacciari, Architecture and nihilism: on the philosophy of modern architecture, New York, Yale University Press, 1993, p. 5).

${ }^{7}$ La noción de Policía a comienzos de la modernidad tiene distintos senti- dos, se utiliza como sinónimo de una comunidad regida por una "autoridad pública"; se refiere también a la manera de gobernar dicha comunidad $y_{\text {, }}$ por último, es sinónimo de "buen gobierno". Todos estos sentidos se conservan intactos, según Foucault entre los siglos XV, XVI y comienzos del XVII. No obstante, entrado el siglo XVIII, adquiere un nuevo sentido: policía se asocia a la necesidad de incrementar las fuerzas del estado, asegurando su "esplendor". Lo esencial en esta época es asegurar la coexistencia de los hombres, de la gran familia que forman, en un territorio, no solo de acuerdo al vivir, sino al incremento de su "bienestar" pues eso redunda en un beneficio directo para el Estado. Bienestar es, precisamente, el término que marca el paso de la preocupación por el "mero vivir" al "vivir bien", asegurando el paso de la necesidad a la felicidad de los individuos como fuente de la fortaleza del Estado (M. Foucault, Seguridad, territorio y población, op. cit., pp. 375-378).

${ }^{8} \mathrm{G}$. Zarone, Metafísica de la ciudad. Encanto utópico y desencanto metropolitano, Valencia, Pre-Textos, 1993, p. 44. El "sentimiento moderno", exclama Le Corbusier, es un espíritu de geometría, de orden y exactitud. $Y$ tal exactitud hoy se nos representa como una necesidad tiránica (Le Corbusier, Urbanisme, París, Flammarion, 1994, p. 36).

${ }^{9}$ A. Kotányi, R. Vaneigem, "Programa elemental de la oficina de urbanismo unitario", Internacional Situacionista (6), 1961. No obstante, el texto "Formulario para un nuevo urbanismo" (Ivain) es el texto que abre la discusión $(\mathrm{H}$. Heynen, Architecture and modernity, Cambridge, London MIT Press, 1999, p. 152).

${ }^{10}$ Nota editorial, "El ocio trabaja", Internacional Situacionista (9), 1964. En la Declaración de Ámsterdam (Constant, Debord, "Declaración de Ámsterdam", Internacional Situacionista (2), Diciembre de 1958) se explica que el urbanismo unitario es la actividad mediante la cual el medio es constantemente recreado según los deseos de los individuos, reunidos colectivamente (Ibid, p. 153)
${ }^{11}$ P. Wollen, "Los situacionistas y la ciudad", NLR (8), Marzo-Abril de 2001، p. 149.

${ }^{12} \mathrm{~A}$. Trachana, "Urbe ludens: espacios para el juego en la ciudad", Ciudad $y$ territorio estudios territoriales, XLVI, 173, 2012, p. 426.

${ }^{13}$ IS, 1964, pp. 130-131.

${ }^{14} \mathrm{~L}$. Mumford, Le déclin des Villes ou la recherche d'un nouvel urbanisme, París, France-Empire, 1970, p. 167

${ }^{15}$ IS, op. cit., p. 132.

${ }^{16}$ Fue precisamente en Alba donde Constant concibe la Nueva Babilonia como un proyecto que pretende acoger gitanos desplazados de la Zona, inspirándose en la manera en que ellos mismos ocupaban el territorio (Constant, La nueva Babilonia, Barcelona, Gustavo Gili, 2009, p. 6).

${ }^{17} \mathrm{~L}$. Andreoti, Le grand jeu à venir. Textes situationnistes sur la ville, París, La Villette, 2007, p. 36.

${ }^{18} \mathrm{H}$. Laborit, L'homme et la ville, París, Flammarion, 1971, p. 161.

${ }^{19}$ IS, op. cit., p. 130.

${ }^{20} \mathrm{lbid}$., p. 134.

${ }^{21}$ F. Careri, Constant. New Babylon, una città nomade, Roma, Testo \& Immagine, 2001, p. 8. Según el geógrafo David Harvey, lector y continuador del pensamiento de Henri Lefebvre, la economía de mercado ha consumado la nihilización del espacio y con ello la desaparición de los valores comunitarios en provecho de la propiedad privada, que asegura la circulación de capital. Desde la emergencia del capitalismo, no es lo natural (el clima, los relieves y sus habitantes) lo que otorga una identidad al territorio, sino la producción económica que explota la tierra y que "otorga una geografía a la producción" (D. Harvey, Géographie de la domination, París, Les Prairies ordinaires, 2008, p. 88).

${ }^{22}$ El urbanismo debe llegar a ser la expresión sin resto de una época, según queda escrito en La carta de Atenas, publicado en 1942, uno de los fundamentales documentos emanados de los CIAM. En el parágrafo 77 se apunta lo siguiente: "las claves del urbanismo se contienen en las cuatro funciones siguientes: habitar, trabajar, recrearse y circular", que puede ser traducido como habitar aisladamente, trabajar en 
la reproducción del sistema, aprovechar el tiempo libre, es decir, consumir, y beneficiarse de una buena circulación, para transitar de un espacio-función a otro.

${ }^{23}$ Nota editorial, "La lucha por el control de las nuevas técnicas de condicionamiento", Internacional Situacionista (1), 1958, p. 12.

${ }^{24} \mathrm{H}$. Lefebvre, Le droit à ville, París, Economica, 1968.

${ }^{25}$ M. Wigley, Constant's New Babylon: the hyper-architecture of desire, Rotterdam, 010, 1998, p. 13.

${ }^{26} \mathrm{Q}$. Stevens, The Ludic City, exploring de potential of public spaces, Abingdon, Routledge, 2007, p. 5.

${ }^{27}$ Ibid., p. 11.

${ }^{28}$ A. Kotányi, R. Vaneigem, op. cit., p. 183.

${ }^{29} \mathrm{lbid} ., \mathrm{p} .184$.

${ }^{30} \mathrm{O}$. Mongin, La condición urbana. La ciudad a la hora de su mundialización, Buenos Aires Paidós, 2006, p. 143.

${ }^{31} \mathrm{X}$. Ventós, Ensayos sobre el desorden, Barcelona, Kairós, 1976, p. 94.

${ }^{32}$ A. Kotányi, R. Vaneigem, op. cit., p. 183.

${ }^{33} \mathrm{Ibid}, \mathrm{p} .184$.

${ }^{34} \mathrm{Ibid}$, pp. 183-184.

${ }^{35} \mathrm{G}$. Debord, La sociedad del espectáculo, Valencia, Pre-textos, 2000, $\S 25$, p. 46.

${ }^{36}$ A. Jappe, Guy Debord, Barcelona, Anagrama, p. 21. 145

${ }^{37}$ G. Debord, op. cit., § 172, p.

${ }^{38}$ Ibid., § 169 p. 144-145.

${ }^{39}$ A. Kotányi, R. Vaneigem, op. cit., p.184.

${ }^{40} \mathrm{lbid}$.

${ }^{41}$ IS, op. cit. p. 134.

${ }^{42}$ Especialmente con Le Droit à la ville, I, (1968); Le Droit à la ville, II Espace et politique, (1972); Du rural à I'urbain, 1970; La Révolution urbaine, (1970); La Production de l'espace (1974). Henri Lefebvre desarrolla con mayor profundidad sus reflexiones sobre la vida cotidiana comenzada en 1946 con Critique de la vie quotidienne. A través de estos textos, una nueva sociología surgía desde el marxismo como bastión de una crítica dirigida contra la expulsión de la dimensión social y cultu- ral de la ciudad, inaugurando un nuevo ejercicio intelectual frente a la falta de un pensamiento (del) ciudadano y (del) cotidiano de la ciudad. El fin consistía en repensar la ciudad y la "sociedad urbana" tras el dominio de un abordaje meramente técnico y económico del espacio social. Este trabajo constituye toda una experiencia de socialización del pensamiento y de reflexión de la experiencia social (Lefebvre VI).

${ }^{43}$ Le Corbusier, op. cit., p. 149.

${ }^{44}$ La "deriva" situacionista, aunque con sus reservas, heredaría la crítica del Dadá y del Surrealismo, en lo que respecta a su apelación a la espontaneidad, la lucha contra la racionalización de la vida en la ciudad. F. Careri, Walkscapes. El andar como práctica estética, Barcelona, Gustavo Gili, 2002, p. 98

${ }^{45} \mathrm{~A}$. Holm, "Urbanisme néolibéral ou le droit à la ville", Multitudes (43), 2010, p. 90.

${ }^{46} \mathrm{H}$. Heynen, op. cit., pp. 159-160.

${ }^{47} \mathrm{~L}$. Busbea, The urban utopia in France, 1960-1970, London, Mit Press, 2007, pp. 30-31.

${ }^{48}$ S. Sadler, The situationist city, Cambridge, Mit Press, 1999, pp. 122123.

49 J. Nichols, "Nomadic Urbanities: Constant's New Babylon and the Contemporary City", Graduate Journal of Asia-Pacific Studies, IV, 2, 2004, 29-52, p. 31

${ }^{50}$ Constant es acusado de venderse al capitalismo al intentar integrar las masas a un ambiente tecnificado $(\mathrm{H}$. Heynen, op. cit., p. 154).

${ }^{51}$ F. Careri, op. cit., p. 8.

${ }^{52}$ Constant, "Auto-dialogue à propos de New Babylon", Opus International, N 27, París, 1971, p. 29.

${ }^{53}$ Constant, "New Babylon", L. Andreotti (ed.), Le grand jeu à venir. Textes situationistes sur la ville. París, La Villette, 2008, p. 223.

${ }^{54}$ F. Careri, op. cit., pp. 10-11. Para Simon Sadler (op., cit., p. 135) el trabajo desarrollado por Constant se haya en relación directa con los proyectos utópicos de Tomas More, Henri de SaintSimon y Charles Fourier, donde la cuestión de los deseos y afectos es esencial.

${ }^{55}$ Constant, op. cit., 224.
${ }^{56}$ L. Mumford, Técnica y civilización, Madrid, Alianza, 1992, p. 302.

${ }^{57} \mathrm{H}$. Heynen, op. cit., p. 153.

${ }^{58}$ F. Careri, op. cit., p. 10.

${ }^{59}$ L. Mumford, op. cit., p. 437.

${ }^{60}$ S. Sadler, op. cit., p. 22.

${ }^{61} \mathrm{M}$. Lussault, De la lutte des classes à la lutte des places, París, Grasset, 2009, p. 88.

${ }^{62}$ M. Wigley, op. cit., p. 9.

${ }^{63} \mathrm{~F}$. Careri, op. cit., p. 11.

${ }^{64}$ Constant, op. cit., p. 225.

${ }^{65} \mathrm{M}$. Wigley, op. cit., p. 17.

${ }^{66} \mathrm{H}$. Heynen, op. cit., p. 159.

${ }^{67}$ Constant, op. cit., p. 224.

${ }^{68} \mathrm{lbid}$.

${ }^{69}$ L. Busbea, op. cit., pp. 116-117.

${ }^{70} \mathrm{~A}$. Trachana, "Consecuencias de New Babylon", Ángulo Recto. Revista de estudios sobre la ciudad como espacio plural, vol. 3, núm. 1, 2011, p. 212.

$71 \mathrm{lbid}$. El antecedente de la megaestructura fue concebido por Le Corbusier, quien había proyectado construir en 1931 un inmueble-viaducto que serviría de soporte a "villas suspendidas" a lo largo del litoral (Eaton, 2001, p. 219).

${ }^{72} \mathrm{R}$. Eaton, Cités idéales. L'utopisme et l'environnement non bâti, Trieste, Fonds Mercator, 2001, p. 219.

${ }^{73}$ S. Sadler, op. cit., pp. 132-135.

${ }^{74}$ R. Eaton, op. cit., p. 222.

${ }^{75}$ L. Busbea, op. cit., p. 128.

${ }^{76} \mathrm{~S}$. Giedion, Construire en France Construire en fer Construire en béton, París, Éditions de la Villete, 2000

${ }^{77}$ Th. Adorno, Minima Moralia. Reflexiones desde la vida dañada, Madrid, Akal, 2006, p. 192

${ }^{78}$ Horkheimer y Adorno, en una dirección análoga, critican la exhortación de Kant por la autonomía del sujeto lanzada en ¿Qué es la llustración? En este escrito Kant expone que la llustración es la salida del hombre de la minoría de edad, de la cual él mismo es culpable (Cf. I. Kant, Filosofía de la historia. Qué es la Ilustración, La plata, Terramar, 2004, p. 33). Esta inmadurez hace referencia al hecho de dejar que otros (creencias, valores, etc.) decidan en lugar del sujeto, por ello la llustración trata de contribuir a su libertad, sin enseñar, ni dirigirle por ningún camino, sino conminándolo a 
servirse de su propio intelecto sin la guía de otro. De manera que, si libertad es en términos modernos la capacidad de darse sus propias leyes para no quedar sujetado por leyes externas de la naturaleza, lo que se logra es establecer un dominio sobre todo lo otro que no provenga del propio sujeto, esto es, sobre la misma naturaleza, que acá aparece enfrentada al dominio del hombre. De esta manera, la llustración es el sistema "que más ayuda al sujeto a dominar la naturaleza. Sus principios son los de la autoconservación. La minoría de edad se revela como la incapacidad de conservarse a sí mismo. El burgués en sus formas sucesivas de propietario de esclavos, empresario libre y administrador, es el sujeto lógico de la llustración" (M. Horkheimer; Th. Adorno, Dialéctica de la ilustración. Fragmentos filosóficos, Madrid, Akal, 2007, p. 92). 


\section{REFERENCIAS}

Adorno, Theodor. 2006. Minima Moralia. Reflexiones desde la vida dañada, Madrid: Akal.

Bentham, Jeremy. 1979. El panóptico. Buenos Aires: La piqueta.

Bonta, Mark and John Protevi. 2004. Deleuze and Geophilosophy. A guide and glossary. Edinburgh: Edinburgh University Press.

Busbea, Larry. 2007. The urban utopia in France, 1960-1970. London: Mit Press.

Cacciari, Massimo. 1993. Architecture and nihilism: on the philosophy of modern architecture. New York: Yale University Press.

Careri, Francesco. 2001. Constant. New Babylon, una città nomade. Roma: Testo \& Immagine.

Careri, Francesco. 2002. Walkscapes. El andar como práctica estética. Barcelona: Gustavo Gili.

Cavalletti, Andrea. 2010. Mitología de la seguridad. La ciudad biopolítica. Buenos Aires: Adriana Hidalgo Editora.

Constant, Debord. 1999. "Declaración de Ámsterdam", In Internacional Situacionista (2), vol. 1: La realización del arte, 61-62. Madrid: Literatura Gris.

Constant. 1971. "Auto-dialogue à propos de New Babylon". Opus International (27): 2931.

Constant. 2009. La nueva Babilonia, Barcelona: Gustavo Gili.

Debord, Guy. 2000. La sociedad del espectáculo. Valencia: Pre-textos.

Eaton, Ruth. 2001. Cités idéales. L'utopisme et I'environnement non bâti. Trieste: Fonds Mercator.

Foucault, Michel. 2006. Seguridad, territorio y población. Curso en el Collège de France 1977-1978. Buenos Aires: FCE.

Giedion, Siegfried. 2000. Construire en France Construire en fer Construire en béton. París: Éditions de la Villete.

Harvey, David. 2008. Géographie de la domination. París: Les Prairies ordinaires.
Heynen, Hilde. 1999. Architecture and modernity. Cambridge: London MIT Press.

Holm, Andrej. 2010. “Urbanisme néolibéral ou le droit à la ville." Multitudes (43): 86-91.

Horkheimer, Max and Theodor Adorno. 2007. Dialéctica de la ilustración. Fragmentos filosóficos. Madrid: Akal.

Jappe, Anselm. 1998. Guy Debord, Barcelona: Anagrama.

Kant, Immanuel. 2004. Filosofía de la historia. Qué es la Ilustración. La Plata: Terramar Ediciones.

Kotányi, Attila and Raoul Vaneigem. 1999. "Programa elemental de la oficina de urbanismo unitario." In Internacional Situacionista (6), vol. 1: La realización del arte, 183-185. Madrid: Literatura Gris.

Laborit, Henri. 1971. L'homme et la ville. Paris: Flammarion.

Le Corbusier. 1957. La carta de Atenas. Paris: Minuit.

Le Corbusier. 1994. Urbanisme. Paris: Flammarion.

Le grand jeu à venir. Textes situationnistes sur la ville. 2008. Ed. Libero Andreotti et al. Paris: La Villette.

Lefebvre, Henri. 1968. Le droit à ville. Paris: Economica.

Lefebvre, Henri. 1970. Du rural à I'urbain. Paris: Anthropos.

Lefebvre, Henri. 1970. La Révolution urbaine. Paris: Anthropos.

Lefebvre, Henri. 1972. II Espace et politique. Paris: Anthropos.

Lefebvre, Henri. 1974. La Production de l'espace. Paris: Anthropos.

Lussault, Michel. 2009. De la lutte des classes à la lutte des places. Paris: Grasset.

Mongin, Olivier. 2006. La condición urbana. La ciudad a la hora de su mundialización. Buenos Aires: Paidós.

Mumford, Lewis. 1970. Le déclin des Villes ou la recherche d'un nouvel urbanisme. Paris: France-Empire. 
Mumford, Lewis. 1992. Técnica y civilización. Madrid: Alianza.

Paquot, Thierry. 2010. L'urbanisation c'est notre affaire!. Nantes: L'Atalante.

Sadler, Simon. 1999. The situationist city. Cambridge: Mit Press.

Stevens, Quentin. 2007. The Ludic City, exploring de potential of public spaces. Abingdon: Routledge. https://doi. org/10.4324/9780203961803

Trachana, Angelique. 2011. "Consecuencias de New Babylon." Ángulo Recto. Revista de estudios sobre la ciudad como espacio plural 3, no. 1: 195-222. http://dx.doi.org/10.5209/ rev_ANRE.2011.v3.n1.19528
Trachana, Angelique. 2012. "Urbe ludens: espacios para el juego en la ciudad." Ciudad y territorio estudios territoriales, XLVI, no. 173: 423-444.

Ventós, Xavier. 1976. Ensayos sobre el desorden. Barcelona: Kairós.

Wigley, Mark. 1998. Constant's New Babylon: the hyper-architecture of desire. Rotterdam: 010 Publishers.

Wollen, Peter. 2001. "Los situacionistas y la arquitectura." New Left Review, no. 8: 138-152

Zarone, Giuseppe. 1993. Metafísica de la ciudad. Encanto utópico y desencanto metropolitano. Valencia: Pre-Textos. 